\title{
Interactivity - A Word in Process
}

\author{
Katja Kwastek \\ Ludwig Boltzmann Institute Media. Art. Research. \\ Kollegiumgasse 2 \\ 4010 Linz, Austria \\ kwastek@media.lbg.ac.at \\ http://media.lbg.ac.at
}

\begin{abstract}
This essay investigates the concept of interactivity by means of a historical analysis of the term itself and its classification. It should be understood as complementary to the essay by Dieter Daniels ('Strategies of Interactivity') in this volume, elaborating on the related artistic and societal contexts and discourses. Understanding the history of a term and its application to the various scientific fields helps to contextualize its denotations and interpretations. Therefore the first part of this essay sources the roots of the term interactivity, adopted by scientific fields as heterogeneous as physiology and sociology, cybernetics and computer science. The second part investigates recent attempts to go beyond a mere definition by further describing and classifying the various processes that are subsumed under the umbrella term of interactivity. The compilation of exemplary studies introduces different approaches of classification, from an ideological or technical, epistemological or aesthetic perspective. As a further step towards new ways of describing and analyzing interactive art, the final paragraph of the essay presents a research project of the Ludwig Boltzmann Institute Media.Art.Research. evaluating a taxonomy for interactive art.
\end{abstract}

\section{1 'Interactivity' and 'Interactive Art'}

The notion of interactivity has come to be a universal catchword of new media and the information society alike. Nevertheless the significance and the value of the term are more than controversial. In a provocative statement, Claus Pias argues: "'Interactivity' is sometimes just as embarrassing as the narrow yellow leather tie that was worn when colorful fractals were modern and chrome balls populated the screens."[1] Whereas Pias is referring to the inflationary use of the notion of interactivity in general, the following quotation refers more specifically to Interactive Art. Wolfgang Kemp, the leading scholar of reception aesthetics in Germany, argues: "The suspicion already expressed in 1984 that 'interactivity aims more to optimize the human-machine relationship than to place technology in the service of communication between people' has not yet been dispelled.[...] In other words, the first bond of this art that seeks to liberate the viewer is the bond to the program. I think that even expert systems, which [...] explicitly seek to promote dialogue and communication cannot simply delete the fact with one key that freedom of choice can only be simulated, not programmed. What is programmed is the illusion of alternatives."[2] 
It is not the intention of this essay to comment on these discussions of the value of the notions of interactivity and interactive art. Instead, its first part sources the roots of the term itself. Understanding the history of the term and its application to the various scientific fields helps to contextualize its denotations and interpretations. The second part of the essay investigates attempts to go beyond a mere definition by further describing and classifying the various processes that are subsumed under the umbrella term of interactivity.[3]

\subsection{The Track Record of a Term}

\subsubsection{The Starting Point: Interaction as Reciprocity}

In general usage the term 'interaction' conventionally denoted 'mutual or reciprocal action or influence'. In the 1901 'Dictionary of Philosophy and Psychology' interaction is defined as: "The relation between two or more relatively independent things or systems of change which advance, hinder, limit, or otherwise affect one another", citing as examples both the body-mind relationship and the interaction of objects in and with the environment, which is frequently also termed reciprocity, according to this dictionary.[4]

\subsubsection{Social Psychology: Interaction as Social Relation}

With the institutionalization of sociology as a science in the early 20th century, the idea of interaction was applied to social and societal processes. In Germany Georg Simmel first used the term interaction ('Wechselwirkung') to characterize interpersonal relationships.[5] In Anglo-American discourses, George Herbert Mead and Edward Alsworth Ross were discussing "social interaction" or the "interaction of human beings".[6] Mead's student Herbert Blumer systematized his research under the term of symbolic interactionism, comparing this in 1937 with the stimulus-response theory. For the proponents of this theory interpersonal interaction consisted of a complex process of causes and effects of the various sensory organs and muscle groups.[7] It was therefore primarily explained physiologically and investigated statistically. The symbolic interactionists, on the other hand, regarded "social interaction as primarily a communicative process in which people share experience, rather than a mere play back and forth of stimulation and response." [8] Whereas the former principally investigated reactions, the latter were more interested in actions.[9]

\subsubsection{Cybernetics: Interaction as Process of Feedback}

A new perspective of processes of interaction opened up around the mid-20th century with the emergence of cybernetic theories: Norbert Wiener, who coined the term cybernetics in 1947, was less interested in the interactions between human beings than in analogies between the self-organization of the human organism and cybernetics. In a book published in 1950, however, he explained how society could also be investigated through analyzing messages and communication processes.[10] Although he focused on processes that could be statistically analyzed, such as the stimulus-response theory that Blumer criticized, his theory of feedback processes 
went beyond the stimulus-response theory in distinguishing between different types of feedback, from reflex-like reactions to systems capable of learning.[11]

\subsubsection{HCI - Interaction as Man-Machine Communication}

It was not until the beginning of the 1960s that computer science had developed to a stage that allowed for the idea of real-time interaction between men and computers: In 1960 J.C.R. Licklider's groundbreaking essay about 'man-computer symbiosis' attempted to "foster the development of man-computer symbiosis by analyzing some problems of interaction between man and computing machines."[12] After the publication of his visionary theories, it took only a few years until the first devices actually enabling real-time interaction between man and computer were built. In 1963, at the Massachusetts Institute of Technology, computer pioneer Ivan Sutherland developed 'Sketchpad', a graphical interface that made it possible to manipulate graphics on a display using a light pen. He explains: "The Sketchpad system makes it possible for a man and a computer to converse rapidly through the medium of line drawings. Heretofore, most interaction between men and computers has been slowed down by the need to reduce all communication to written statements that can be typed; in the past, we have been writing letters to rather than conferring with our computers.[...It] opens up a new area of man-machine communication."[13]

A year before that, Douglas Engelbart, founder of the 'Augmentation Research Center' at the Stanford Research Labs, had already published his program for 'Augmenting Human Intellect'. The most famous outcome of this program, patented in 1968 but already developed around 1965, was the "X-Y position indicator for $a$ display system", now known as the computer-mouse. With the principal concept of the graphical user interface developed by Sutherland, and Engelbart's mouse replacing the light-pen, basic elements of the human-computer interface were available. From then on, human-computer interaction was established as a highly specialized and interdisciplinary field within computer science.[14]

This overview shows that by the early 1960s the concept of interaction had developed from an idea of reciprocity in biological, chemical and physiological processes into elaborate theories of social interaction (sociology), into a whole new science trying to establish the idea of feedback processes as a basic theorem of life and technology (cybernetics), and into a field of research and development in the computer sciences (HCI). But when did it enter the arts?

\subsection{Towards 'Interactive Art'}

Whereas it is relatively easy to answer the question of when the notion of Interactive Art first appeared (see below), the history of the concept of interaction within the arts is more complex. My suggestion is that the emergence of each of the three fields of knowledge identified above (sociology, cybernetics and computer science), with their respective concepts of interactivity, had a parallel in the arts.

\subsubsection{Participatory Art Projects}

The consideration of social interaction as a possible element of artistic projects arose more or less parallel to its story of success in the social sciences. Initial attempts to 
involve the public can be traced back to the classical avant-garde, although the breakthrough of these new artistic concepts did not occur until after WWII. Though these projects are extremely important for the development of the arts up to the present,[15] they are not commonly called 'interactive', but participatory or collaborative. Nevertheless the concepts of the participatory and collaborative works have always been considered an important point of reference for media based art and taken into consideration for comparative judgments about artworks using technical feedback-processes. Yet even in the 1960s, the concepts concerning the relationship between art and technology were heterogeneous. As Dieter Daniels elaborates in his essay ('Strategies of Interactivity') in this volume, artists like John Cage, Nam June Paik and Valie Export investigated the manifold interrelations of participatory ideas and the power of mass media. Meanwhile other artists were more interested in the technological feedback processes themselves, often referring to visions of Artificial Intelligence. The latter have to be seen in close relation to cybernetic theories.

\subsubsection{Cybernetic Art}

The second field of knowledge introducing concepts of interaction into the arts - even if to a lesser extent - were the ideas of cybernetics. Already in the 1950s, the Hungarian sculptor Nicholas Schoeffer built his 'Cybernetic Spatiodynamic Sculptures'. He used the cybernetic concept of the homeostat to organize the reaction of these works to the environment via sensors. He was followed in the 1960s by artists like James Seawright, Edward Ihnatowicz and Tony Martin. They built devices that would interact with their environment in one way or another, mostly via light and sound sensors. Or they installed environments that reacted to the audience, emitting light and/or sound. Yet they did not call their works interactive either. Instead, they were called cybernetic, responsive or reactive.[16]

In 1968 Jack Burnham, author of numerous books and essays attempting to contextualize cybernetic art within art history, observes the growing differences between cybernetic artworks and the achievements of computer science: "The spectacle of an artifact adjusting to its environment through a series of visible maneuvers has a certain anthropomorphic fascination, but it remains hardly an efficient way of handling immense amounts of information. It is well to mention this because the gap between the romantic prototype robot - surely a leftover from the first age of machines - and the modern theory of automata is an ever-widening one." [17]

\subsubsection{Interactive Art}

Though the challenge of implementing computers was already discussed within the realm of cybernetic art, only very few works were actually based on algorithmic processes.[18] Even though computer science had successfully developed the possibilities of human-computer interaction in the 1960s, the adoption of these technologies in the arts happened very slowly.

In 1969 a group of artists and scientists set up an installation entitled 'Glowflow' in the Union Main Gallery of the University of Wisconsin. Inside a dark room, phosphorescent particles were circulating in tubes. The tubes ran through columns with integrated lights, which were illuminated by the visitors through touch-sensitive 
floor pads. These lights in turn caused the phosphors to glow. The subtitle of the work still followed the conventions of cybernetic artworks. It was called: "Glowflow, $a$ computer-controlled, light sound viewer responsive environment". But the flyer accompanying the exhibition introduced the term Interactive Art: "Glowflow is not an exhibit in the traditional sense, but a continuous experimentation in interactive art. Its basic elements - lights, sounds and viewers - interact through control devices which are programmed by the artist-researcher to explore a variety of relationships. While many exhibits in the past have established predetermined relationships of viewer to environment, Glowflow is capable of going beyond fixed interactions. With a computer as a control device, it is possible to explore much more dynamic viewerenvironment relationships." [19]

It is in this text that the notion of Interactive Art is first coined and at the same time related to the implementation of the computer as control device.

One of the co-creators of this project was Myron Krueger, who is now regarded as the pioneer of Interactive Art. His concept of interactivity was developed from experiences with Glowflow.[20] Rather than focusing on the creation of sculptures or robot-like creatures, he started with the idea of the responsive environment, augmented its sensorial capacities installing video cameras, elaborated its operative options by using computers as control devices, and extended its reactive capacities by projecting computer graphics onto the walls.

Although it was not until the 1990s that 'Interactive Art' became the catchword of new media art,[21] the origins of the term can be traced back to 1969. The tendency to restrict the term to computer controlled interactions also goes back to the same period:

The activities of communication arts of the 1970s and 1980s, such as artworks conducted by Robert Adrian X, Kit Galloway and Sherrie Rabinowitz, Douglas Davis and others, were not commonly referred to as Interactive Art. Nevertheless they received far more attention than the contemporaneous, scarcely known pioneers of computer-controlled installations such as Myron Krueger, Lynn Hershman, Jeffrey Shaw or Grahame Weinbren.[22] It was only with the advent of the Word Wide Web, when communication arts were identified as predecessors of net art, i.e. computer controlled communication art, that their interrelations started to become more evident.

As more and more artists created various kinds of 'interactive artworks' in the 1990s, it became increasingly obvious that there was an ambiguity between the term in the narrow sense of computer controlled interaction and its denotations resulting from the various concepts of interactivity that had emerged throughout the previous nearly 100 years.

The different discourses that accompanied these interpretations and developed along the various implementations of interactive technologies over the years are elaborated in detail by Dieter Daniels. The focus of the present essay, however, is on the fact that the awareness of the ambiguity of the term led to a growing number of attempts to investigate the different strategies, technical processes and intentions it stands for.

\subsection{The Necessity of Distinctions}

The second part of this essay summarizes attempts to describe and classify the processes understood as interactive. There are various reasons why such a compilation can never 
be exhaustive. One is the still sketchy state of research concerning classifications of interaction processes in the various disciplines; another is the interdisciplinary nature of the field, where entirely different perspectives on the same phenomenon impede a comprehensive synopsis. But most of all, the object of research itself is constantly changing and therefore subject to ongoing revisions of the related discourses.

\subsubsection{Ideological Versus Instrumental Views of Interactivity}

In their 'Critical Introduction' to New Media Martin Lister et al. distinguish between 'ideological' and 'instrumental' views of interactivity.[23] This is comparable to the distinction suggested by Dieter Daniels, who identifies interactivity as both an ideology and a technology. Nevertheless, Lister's compilation of ideological views is interesting in this context, because he focuses on the interrelation of the differing perspectives and the various disciplines they stem from. While information technology within the scope of research on HCI understands interactivity as a possibility for controlling and intervening in computer processes, communication studies gauge interactivity according to face-to-face situations.[24] Media studies, on the other hand, assume a latent interaction between the receivers and the objects of their interest consisting of the processes of selection and interpretation.[25] Like Daniels, Lister et al. cite as a further important perspective on aspects of interactivity the idea of "grassroots democratic exchange" as a counter-pole to the one-to-many strategy of the mass media, which understands interactivity as the co-determination and exchange possibilities of the members of one or more societies.[26]

\subsubsection{Degrees of Interactivity}

Categorizations that Lister describes as 'instrumental' are often still closely related to 'ideology', i.e. the different political, philosophical and economic goals associated with concepts of interactivity. This becomes apparent when the categorization of interactive processes attempts to create scales ranging from a low to a high degree of interactivity.

Beryl Graham, who provides a valuable compilation of categorization attempts, bases her classifications upon the division proposed already in 1977 by Cornock and Edmonds.[27] They distinguish between static and dynamic art systems,[28] with the latter divided into

- dynamic systems, that are based on an organizational dependence on environmental variables.

- reciprocal systems that treat the spectators as environment, with responses through time.

- $\quad$ participatory systems with a focus on the interpersonal reactions of a group of participants to a situation specified as a matrix.

- interactive systems that offer a mutual exchange between man and machine, elaborately related on either side of an interface.

Graham modifies this taxonomy using a metaphor of conversation, but sticking to the idea of the 'real conversation' as the highest degree of interaction, "a category which is a possibly unobtainable end point but remains as a possible future aim."[29] 
Lutz Goertz also qualifies degrees of interactivity, but he proposes determining them based on the interplay of various factors.[30] He suggests a consideration of the degree of selection options, the degree of modification options, the quantitative size of selection and modification possibilities, and the degree of linearity or non-linearity. In this way, he acknowledges that there are qualitative as well as quantitative differences within possibilities of selection or modification and that they should be related to the question of timing. With this question he refers to the possibilities of coauthoring the course and order of the interactive processes enabled.

While breaking down interactivity processes into the categories of selection, modification and (non-)linearity is an interesting approach, the general tendency to draw up scales according to degrees of interactivity is questionable, at least in the field of the arts. Judging the quality of media-based interaction by a comparison with direct communication disregards the fact that the decision to use media for an artwork is a deliberate one. The objective of interactive media art is precisely to uncover and reflect the specific forms of interaction enabled by new media.[31]

Categories describing interactive artworks should therefore attempt to identify and denominate the different processes taken into consideration by the artists and analyze their relation to the discursive backgrounds and concepts of interaction they refer to, irrespective of a validation of an assumed gradation.

Although Lister et al. also adhere to some extent to the idea of degrees of interactivity, in their delineation of the 'instrumental view' they attempt a description of specific characteristics of interaction processes. They distinguish between hypertextual versus immersive navigation as well as between registrational interactivity and interactive communication. Hypertextual navigation, according to Lister, is based on choices available from a pool of data to construct an individual 'text'. They equate this kind of interaction with Peter Lunefeld's definition of 'extractive' interaction.[32] Immersive navigation, on the other hand, focuses on the investigation of spatially organized information: "We might say that the navigation of immersive media environments is similar to hypertextual navigation, but with additional qualities [...] Instead of a text-based experience aimed at finding and connecting bits of information, the goals of the immersed user will include the visual and the sensory pleasures of spatial exploration."[33]

With registrational interactivity they describe the possibility of storing one's own data, which then become part of the 'text'. Interactive communications define a computer-aided human-to-human communication, which they again relate to the idea of gradation:

"When email and chat sites are considered from the point of view of human communication, ideas about the degree of reciprocity between participants in an exchange are brought into play. So, from a Communication Studies point of view, degrees of interactivity are further broken down on the basis of the kinds of communication that occur within CMC. Communicative behaviors are classified according to their similarity to, or difference from, face-to-face dialogue, which is frequently taken as the exemplary communicative situation which all forms of 'mediated' communication have to emulate."[34]

While their study gives a valuable description of different types of interactivity, it clearly focuses on text-based interactions and is therefore far from being 
complete.[35] It is hardly possible to analyze all the different kinds of interaction that employ tactile devices or serve as a tool or instrument for performing specific tasks with these categories. In recent years there has been a growing desire to transcend the focus on the graphical interface, in media arts as well as in the realm of interface design. A considerable amount of research has already been conducted, for example, on notions of mediated embodiment [36] or the idea of device art.[37]

\subsubsection{Epistemological and Aesthetic Categories}

On a more general level it is doubtful whether the aforementioned ideological and instrumental views of interactivity would constitute a sufficient base for a thorough research of artistic projects in the realm of media-based interaction, even if they were broken down into a comprehensive compilation of the specialized studies. The classifications summarized so far do not investigate artworks specifically, but are applicable to all kinds of interactive media. Within the arts, epistemological and aesthetic concepts play a seminal role in the artist's realization of their ideas and in what the participant may gain from the artwork. Often the insights and aesthetic processes encouraged by different interactive works do not correspond to the instrumental categorizations available. For example, a hyperlink system may offer a non-linear narration of a story, but it may also involve the viewer in a question and answer session. The storage of user-inputs may serve as a surveillance device, but also as a means of co-creating a multimedia environment.

Therefore, there is a need for approaches that denominate the epistemological intentions of the works and identify the processes that enable their mediation. Two examples may suffice to illustrate possible steps in this direction:

In his extensive historical overview of 'Closed Circuit Video Installations' Slavko Kacunko does not deal exclusively with works that allow for digital feedback processes.[38] On the contrary, his explicit decision to neglect the distinction of algorithmic versus non algorithmic feedback processes is based on the realization that - from an epistemological point of view - the works conventionally called 'closed circuit installations' and the works conventionally called 'interactive installations' have common characteristics. He breaks down the various artistic concepts distinguishing different strategies of subject/object relations, reality constructions, system models and behavior patterns, and game concepts and learning processes. In relation to reality constructions, he distinguishes between the creation of reality models, posttechnological visions and their psychological effects, computer-aided media reflections and interlocking levels of reality and virtuality. Kacunko thus concentrates on the philosophical views and models implied within the different interactive strategies.

A second example for the various possibilities of going beyond instrumental classifications is the approach of Jean-Louis Boissier, media artist from Paris. He focuses on the structural or aesthetic issues in the interaction process. He describes how, in the course of his own artistic work, he was able to identify certain 'figures of interaction' that had emerged. He distinguishes between figures that are generated from internal structures and those that describe attitudes on the part of recipients. The internal figures he identifies are forking ("bifurcation"), break/interruption ("suspension"), change ("mutation") and transfer ("réversion"). The recipients, 
according to Boissier, may conduct actions of comparison ("comparaison"), description ("désignation"), distancing ("distanciation") and empowerment ("procuration").[39]

Unlike Kacunko's suggestion, Boissier's terms do not try to embrace the philosophical backgrounds of the works, but constitute a first attempt to describe the single (also partial) processes that together constitute their structural and receptional characteristics.

\subsubsection{Case Study Prix Ars Electronica}

As yet another step within the attempts to identify suitable descriptive models for interactive art, the Ludwig Boltzmann Institute Media.Art.Research. is conducting a case study based on the entries for the annual competition of the Prix Ars Electronica. On the basis of research into former approaches to categorizations (summarized above) we developed a tentative taxonomy that we applied to the more than 350 entries of the 2007 competition. The taxonomy was adapted in process, thus reacting to the works that were actually entered by the artists in this category and thereby defined as interactive by them. While the project also investigates questions of the form and range of the works, the media applied and the topics covered, the focus here is on the more specific categories of interaction.[40] With the classification of interaction processes we soon realized that describing them with nouns is problematic. Gerhard Dirmoser, an Austrian system analyst, suggested testing descriptions in verb form instead. The advantages are obvious: whereas a noun may be suitable for describing a process, it leaves open the question of the direction/perspective of the process. A verb, on the other hand, urges the user to specify the subject of the process. When the word 'observation' is used, for example, it is unclear whether the work is meant to observe the viewer or vice-versa. If one instead formulates the categorization as 'the viewer can - observe,' then the direction of interaction is clear.

Our suggestion is to first identify the partners involved in the interaction process. Once the interaction partners have been specified, there should be a further definition of the type of interaction that is enabled. We suggest describing whether the visitor / performer is encouraged to observe, to explore, to activate, to control, to select, to navigate, to participate, to leave traces or store something or to exchange information and of course further activities should be added.

But there is also another part of the interaction process that originates from the work or mediating device. The work may tell or narrate something, document or inform, visualize or sonify, it may be built to enhance perception or to offer a game, to monitor something or to serve as an instrument, to transform, to collect and store, to process or mediate.

The compilation of a rich variety of verbs describing the various activities and strategies relevant to interaction processes should improve the possibilities for describing and analyzing interactive media art.

To further evaluate this approach, we are providing this taxonomy for the artists to be applied by them during the 2008 competition entry process. We hope that this 
project will contribute to the attempts to develop a suitable vocabulary for the manifold field of Interactive Art.

The scope of these suggestions, as well as the scope of the present essay, is not to determine a fixed set of normative categories. Rather they provide an extendible but still comprehensive vocabulary that helps to differentiate between the various types, strategies and intentions of interactive processes and artworks. They will hopefully encourage further discussion and new interesting concepts of interactivity. As media artist Michael Naimark states, referring to the Boltzmann Institute's taxonomy project: "lists like these serve two different functions: 1) they help organizers organize and 2) they encourage artists to do something 'unclassifiable'. Both are noble goals. "[41]

\section{References}

1. Pias, C.: Chimäre Interaktivität: Wohin gehen wir, wenn wir drin sind? In: Texte zur Kunst 58, pp. 92-103 (2005); here p. 1 (transl. Aileen Derieg)

2. Kemp, W.: Zeitgenössische Kunst und ihre Betrachter. Positionen und Positionszuschreibungen. In: ibid (ed.) Zeitgenössische Kunst und ihre Betrachter. Jahresring 43, pp. 13-43 (1996); here p. 19 (transl. Aileen Derieg)

3. They attempt to cover more than 100 years of a term's history and breakdown can of course only offer a very rough and exemplary summary of the relevant objectives and theories. The references given in the footnotes try to compensate this deficit by suggesting further readings

4. Baldwin, J.M. (ed.) Dictionary of Philosophy and Psychology. The German translation Baldwin offers for 'interaction' is 'Wechselwirkung', London, vol. 1, p. 561 (1901) (in German)

5. Cf. Abels, H.: Einführung in die Soziologie. In: Die Individuen in ihrer Gesellschaft, Wiesbaden, 2nd edn., vol. 2, pp. 204-206 (2004)

6. Ross, E.A.: Social Psychology. An Outline and Source Book, New York, p. I (1909,1st edition 1908); Mead, G.H.: Social Psychology as Counterpart to Physiological Psychology. The Psychological Bulletin VI(12), 401-408 (1909); Cf. The history of the term in Hans Dieter Huber: Der Traum vom Interaktiven Kunstwerk (2006), http://www.hgb-leipzig.de/ artnine/ huber/aufsaetze/nt.html (October 24, 2007); I would like to thank Gunther Reisinger calling my attention to this essay

7. Cf. Blumer, H.: Social Psychology. In: Schmidt, E.P. (ed.) Man and Society. A Substantive Introduction to the Social Sciences, New York, pp. 144-198, here p. 170 (1937)

8. Ibid., p. 171

9. Ibid., p. 191

10. Wiener, N.: The Human Use of Human Beings. Cybernetics and Society, New York, p. 16 (1954,1st edition 1950)

11. Ibid., p. 33

12. Licklider, J.C.R.: Man-Computer Symbiosis. IRE Transactions on Human Factors in Electronics, HFE-1, 4-11 (1960), http://groups.csail.mit.edu/medg/people/psz/Licklider.html (October 24, 2007)

13. Sutherland, I.E.: Sketchpad: A Man-Machine Graphical Communication System, PhD thesis, Massachusetts Institute of Technology, reprinted as 'Electronic Edition', University of Cambridge, Computer Laboratory, Technical Report 574 (2003), here p. 17, http://www.cl. cam.ac.uk/techreports/UCAM-CL-TR-574.pdf; See Preface to 'Electronic Edition' by Alan Blackwell and Kerry Rodden for further contextualization 
14. A good overview of early developments in this field is provided by Brad. Myers, A.: A Brief History of Human Computer Interaction Technology. ACM interactions 5(2), 44-54 (1998), An extensive recent compilation is offered by Bill Moggridge: Designing Interactions, Cambridge, MA (2007), http://www.cs.cmu.edu/ amulet/papers/uihistory.tr. html (October 24, 2007); Thanks to my colleague Guenther Kolar for reviewing this this paragraph

15. A good compilation of texts relating to participatory art and a comprehensive literature survey can be found in Bishop, C., Participation, London/Cambridge, MA (2006)

16. The first attempt to contextualise cybernetic arts within art history was conducted by Jack Burnham. Burnham, J.: Beyond Modern Sculpture. The Effects of Science and Technology on the Sculpture of the Century, New York (1968) See also my more detailed investigation into the objectives of cybernetic arts: Katja Kwastek: The Invention of Interactivity In: Daniels, D., Schmidt, B.U. (eds.): Artists as Inventors, Inventors as Artists, Ostfildern (forthcoming, 2008)

17. Burnham, p. 338 (1968) (see note 16)

18. Cf. exhb. cat.: Software. Information technology: its new meaning for art. Burnham, J. (ed.), New York, p. 11 (1970)

19. Exhibition flyer. Archive of Myron Krueger

20. Cf. Krueger, M.: Artificial Reality II, Reading (1991)

21. Even though he used the term 'Interactive Art' in his publications, Krueger himself preferred the term 'artificial reality' to generally characterize his activities

22. For a detailed investigation of these 'pioneers'. Dinkla, S.: Pioniere Interaktiver Kunst, Ostfildern (1997)

23. Lister, M., et al.: New Media. A Critical Introduction. London (2003)

24. The more computer-aided interactivity approaches real interaction between two or more persons, the more successful it is according to this view. Lister, et al., p. 43 (2003) (see note 23)

25. There is a perspective on interactivity, based in literary and media studies, that argues that nothing much has changed in principle. We are just offered more opportunities for more complex relationships with texts, but these relationships are essentially the same. Lister, et al., p. 43 (2003) (see note 23)

26. Lister, et al., p. 44 (2003) (see note 23)

27. Graham, B.: A Study of Audience Relationships with Interactive Computer-Based Visual Artworks in Gallery Settings, through Observation, Art Practice, and Curation, Ph. D. University of Sutherland (July 1997), http://www.sunderland.ac.uk/ as0bgr/cv/sub/thesis. pdf (July 3, 2007)

28. Cf. The more recent publication, which however still adheres to the same categories: Candy, L., Edmonds, E.: Interaction in Art and Technology. Crossings. eJournal of Art and Technology 2.1 (2002), http://crossings.tcd.ie/issues/2.1/Candy/ (July 3, 2007)

29. Graham, p. 137 (1997) (see note 27)

30. Goertz, L.: Wie interaktiv sind Medien (1995) In: Bieber, C., Leggewie, C. (eds.) Interaktivität. Ein transdisziplinärer Schlüsselbegriff, Frankfurt, pp. 97-117 (2004)

31. See for example: Huhtamo, E.: Seeking Deeper Contact. Interactive Art as Metacommentary. Convergence 1(2), 81-104 (Autumn 1995)

32. Lunenfeld, P.: Digital Dialectics: a hybrid theory of computer media. Afterimage (April 21, 1993)

33. Lister, et al., p. 21 (2003) (see note 23)

34. Lister, et al., p. 22 (2003) (see note 23) 
35. Thanks to the students of Interface Culture at the University of Art and Design, Linz for a revealing discussion of Lister's publication

36. Cf. Dourish, P.: Where the Action is. The Foundation of Embodied Interaction, Cambridge, MA (2004)

37. Cf. Kusahara, M.: Device Art: A New Form of Media Art from a Japanese Perspective. Intelligent agent 6(6) (2006), http://www.intelligentagent.com/archive/Vol6_No2_pacific_ rim_kusahara.htm (October 24, 2007)

38. Cf. Kacunko, S.: Closed Circuit Videoinstallationen. Ein Leitfaden zur Geschichte und Theorie der Medienkunst mit Bausteinen eines Künstlerlexikons, Berlin (2004); also Kacunko's discussion of concepts of Interactive Art, ibid., pp. 54-62

39. Boissier, J.-L.: La rélation comme forme. L'interactivité en art, Geneva, p. 289 (2004)

40. The extensive report of the research project, http://gams.media.lbg.ac.at:8080/fedora/get/ o:ia-079-2/bdef:PDF/get/

41. E-Mail to the author (December 13, 2006) 